KCP.613-5432

Distribution Category UC-706

Approved for public release; distribution is unlimited.

\title{
PLASTIC ENCAPSULATED PARTS
}

Timmy Castillo

Published October 1994

Final Report

Timmy Castillo, Project Leader 


\section{DISCLAIMER}

This report was prepared as an account of work sponsored by an agency of the United States Government. Neither the United States Government nor any agency thereof, nor any of their employees, make any warranty, express or implied, or assumes any legal liability or responsibility for the accuracy, completeness, or usefulness of any information, apparatus, product, or process disclosed, or represents that its use would not infringe privately owned rights. Reference herein to any specific commercial product, process, or service by trade name, trademark, manufacturer, or otherwise does not necessarily constitute or imply its endorsement, recommendation, or favoring by the United States Government or any agency thereof. The views and opinions of authors expressed herein do not necessarily state or reflect those of the United States Government or any agency thereof. 


\section{DISCLAIMER}

Portions of this document may be illegible in electronic image products. Images are produced from the best available original document. 


\section{Contents}

$\begin{array}{ll}\text { Section } & \text { Page }\end{array}$

Abstract $\ldots \ldots \ldots \ldots \ldots \ldots \ldots \ldots \ldots \ldots \ldots \ldots \ldots \ldots \ldots \ldots \ldots \ldots$

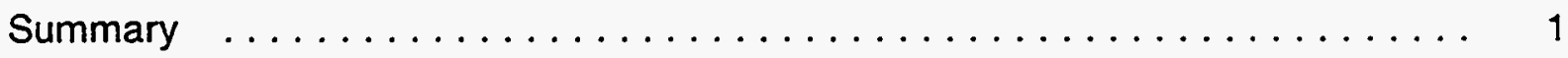

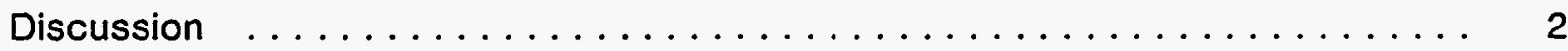

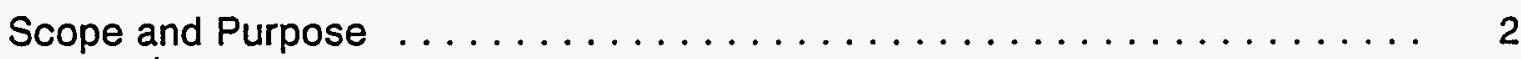

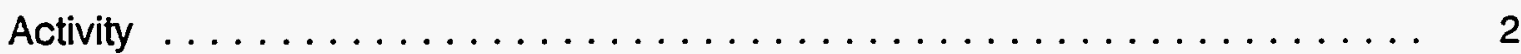

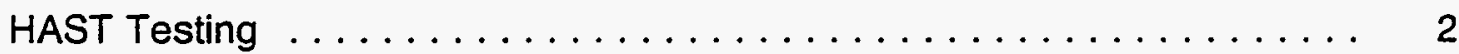

Failure Analysis Results $\ldots \ldots \ldots \ldots \ldots \ldots \ldots \ldots$

Moisture Absorption and Failure Analysis Concerns . . . . . . . . . 10

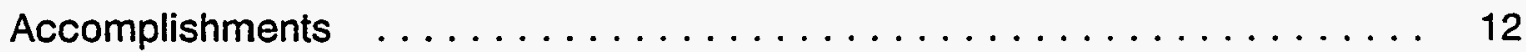

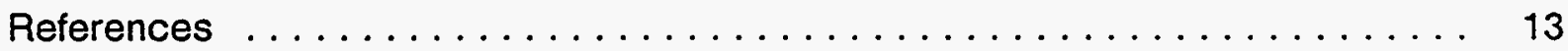

Appendix. NPN Transistor Test Data $\ldots \ldots \ldots \ldots \ldots \ldots \ldots \ldots \ldots$ 


\section{Illustrations}

Figure $\quad$ Page

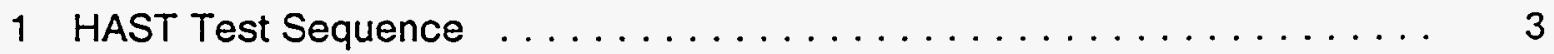

2 Electrical/Mechanical Test Sequence $\ldots \ldots \ldots \ldots \ldots \ldots$

3 SEM Cavity Overview Showing an NPN Transistor Die Sheared From the Gold/Silicon Die Attach $\ldots \ldots \ldots \ldots \ldots \ldots$

4 MOSFET With Cracked Epoxy Package $\ldots \ldots \ldots \ldots \ldots \ldots \ldots$

5 SEM Photo of Fractured MOSFET Die $\ldots \ldots \ldots \ldots \ldots$

\section{Tables}

Number $\quad$ Page

1 Material Contents of Plastic Devices $\ldots \ldots \ldots \ldots \ldots$

2 Electrical/Mechanical Test Results $\ldots \ldots \ldots \ldots \ldots \ldots \ldots \ldots$

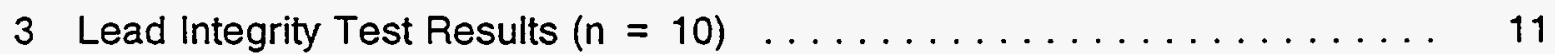

4 NPN Transistor Temperature Cycling $\ldots \ldots \ldots \ldots \ldots \ldots$ 


\begin{abstract}
Plastic semiconductor packages were characterized as possible alternatives for canned devices, which are susceptible to internal shorts caused by conductive particles. Highly accelerated stress testing (HAST) as well as electrical and mechanical testing were conducted on plastic technology devices.
\end{abstract}

\title{
Summary
}

The study of plastic semiconductor technology has an increasing importance for military users in today's environment. With decreased defense budgets, suppliers, in an effort to remain profitable, have opted for purchase of foreign-made semiconductor devices. The resulting reduction in the domestic supplier base for high-reliability military applications has prompted a growing interest in plastic semiconductor package technology. Plastic package technology can provide high volume at low cost. Plastic parts have an advantage for military applications because they are voidless, which does not allow an opportunity for shorts caused by conductive particles.

Compared to hermetic cans and ceramic packages, plastic packages have advantages such as mass production and low cost, but the disadvantage is moisture absorption (because they are nonhermetic). Plastic devices absorb and permeate moisture more than other package types. The absorption of moisture can result in corrosion or package cracking called the "popcorn effect." The success of plastic part technology has been led by the wide use of commercial products (that is, TV, radios, and computers).
Because absorption and permeation of water through polymer materials are inevitable, the most serious problem in plastic encapsulated devices is aluminum metallization corrosion in moist atmospheres, which leads to functional failures of the devices.

A study was performed on plastic parts in order to assess the suitability of these packages for high-reliability applications. Two groups of parts were evaluated: one evaluation considered the NPN transistor; the other examined a MOSFET.

The NPN transistors experienced the highest fallout (catastrophic).

Approximately $61 \%$ failed after 30 hours in the initial phases of the HAST intervals. The MOSFETs appeared to be more robust throughout the complete HAST intervals. They experienced no failures (catastrophic) after 70 hours of HAST intervals.

It is not known what factor may have contributed to the robustness of the MOSFETs. Speculation is that because the MOSFET is a bigger package, the fabrication process may differ from that of the NPN transistor. 


\section{Discussion}

\section{Scope and Purpose}

This project explored the use of plastic semiconductor packages as a possible alternative for canned devices - which are susceptible to internal shorts caused by conductive particles. Of special concern was the ability of plastic semiconductor packages to malfunction because of moisture absorption.

A study was performed on plastic semiconductor packages to assess their suitability for high-reliability applications. The parts evaluated were one group of NPN transistors and another group of MOSFETs. The evaluation included highly accelerated stress testing (HAST), as well as electrical and mechanical testing of the plastic technology devices. The project sought to develop the capability to perform a satisfactory method of failure analysis for plastic technology devices.

\section{Activity}

\section{HAST Testing}

The devices underwent HAST testing by Sandia National Laboratory at $140^{\circ} \mathrm{C}$ binary testing and $85 \%$ relative humidity with bias applied (32V Vcb, emitter open). The HAST test sequence is described in Figure 1. Separate additional testing (electrical and mechanical) was performed as described in Figure 2.

A thorough construction analysis separate from this report was performed. The results can be found in the project file. The material makeup is summarized in Table 1.
The NPN transistors were exposed to the following HAST intervals: $10,20,30,50$, and 100 hours with post-interval electricals. The MOSFETs were exposed to the following HAST intervals: $10,20,30,50,70$, $100,150,200$, and 500 hours with postinterval electricals.

The NPN transistors experienced the highest fallout (catastrophic). The NPN transistor is a low-power switching transistor assembled in a three-lead plastic package using gold/silicon eutectic die attach and thermocompression gold wire bonds. Approximately $61 \%$ failed after 30 hours in the initial phases of the HAST intervals.

The MOSFETs appeared to be more robust throughout the complete HAST intervals. They experienced no failures (catastrophic) after 70 hours of HAST intervals.

Only the catastrophic failures were removed from both groups - catastrophic being excessive leakage; otherwise, the devices remained in the population during the HAST intervals. The excessive early failures of NPN transistors may have been accelerated by the bias conditions of the devices during HAST. The emitter was left open, which may have caused the emitterbase junction to go into avalanche breakdown.

It is not known what factor may have contributed to the robustness of the MOSFETs. The MOSFET is a bigger package and it is thought that the fabrication process may differ from that of the NPN transistor. The MOSFET does contain copper for the base metal in the leads and paddle core (die mount area) 


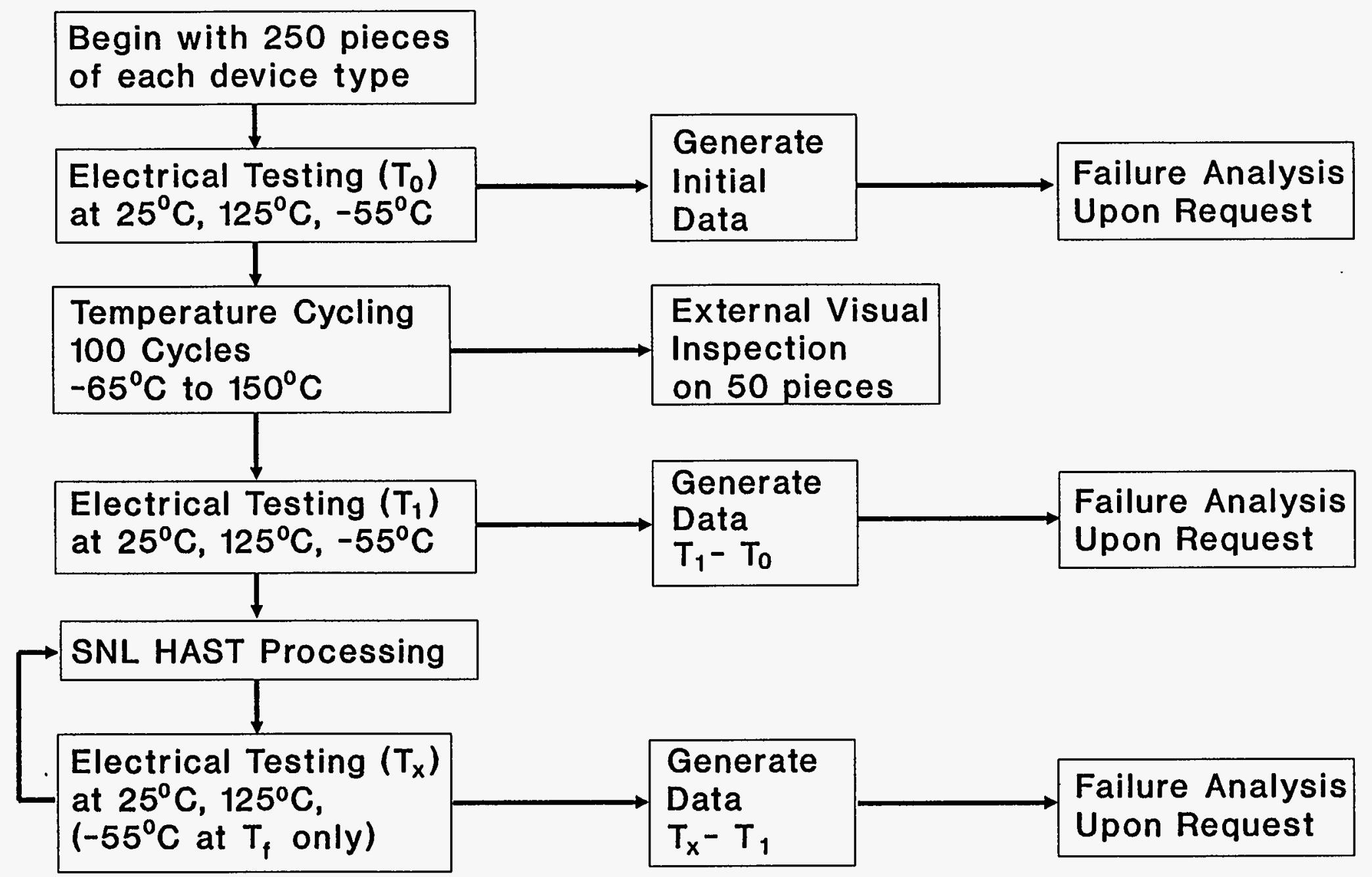

Figure 1. HAST Test Sequence 
$25^{\circ} \mathrm{C}$ Electrical

$-55^{\circ} \mathrm{C}$ Electrical

$150^{\circ} \mathrm{C}$ Electrical

Constant Acceleration

Post-Acceleration Endpoints

Vibration

Post-Vibration Endpoints

Mechanical Shock

Post-Mechanical Endpoints

High-Temperature Storage

Post-Temperature Endpoints

Lead Fatigue

Post-Lead Fatigue Electrical

Lead Tension

Collector Lead

Temperature Cycling

Post-Temperature Endpoints

Fine Leak

Gross Leak

Pre-Burn-in Electrical

Pre-Op. Life Electrical

Burn-in

Post-Burn-in Electrical

Op. Life

Post-Op. Life Electrical

HTRB

Post-HTRB Electrical

Post-HTRB Solderability

Pre-HTFB Electrical

HTFB

Post-HTFB Endpoints

(XTOR)

(XTOR)

(XTOR)

(XTOR)

(XTOR)

(XTOR)

Post-HTRB Endpoints

Pre-Bias Electrical

Bias Life

Post-Bias Life Endpoints

Figure 2. Electrical/Mechanical Test Sequence 
Table 1. Material Contents of Plastic Devices

\begin{tabular}{||l|l|l||}
\hline \hline Location in Device & NPN Transistor & MOSFET \\
\hline Plastic Encapsulant & $\mathrm{Si}, \mathrm{Sb}, \mathrm{Br}, \mathrm{C}, \mathrm{O}$ & $\mathrm{Si}, \mathrm{Sb}, \mathrm{Br}, \mathrm{C}, \mathrm{O}$ \\
\hline Paddle Core & $\mathrm{Cu} / \mathrm{Fe}$ & $\mathrm{Cu}$ \\
\hline Paddle Finish & $\mathrm{Cu}$ & $\mathrm{Ni}$ \\
\hline Lead Core & $\mathrm{Cu} / \mathrm{Fe}$ & $\mathrm{Cu}$ \\
\hline Lead Plating & $\mathrm{Cu}$ & $\mathrm{Ni}$ \\
\hline Lead Finish & $\mathrm{Pb} / \mathrm{Sn}$ & $\mathrm{Pb} / \mathrm{Sn}$ \\
\hline
\end{tabular}

with nickel plating; that may contribute to a better adhesion between the metals and the plastic. Both devices are made from the same plastic molding material (Table 1).

\section{Failure Analysis Results}

A couple of failures for the NPN transistor, one at 10 and one at 30 post-HAST hours, were evaluated. It was discovered that the die had sheared away from the die attach area (see Figure 3). The failure analysis report concludes that the glass transition temperature was exceeded, which resulted in the shearing of the die.

Additional failures were evaluated but were inconclusive. The failure analysis report states that the failures were caused by the units being electrically overstressed. This conclusion was verified by revisiting the bias condition of the transistors (emitter open). As mentioned earlier, it was concluded (failure analysis) that leaving the emitter open causes the emitter-base junction to result in avalanche breakdown, which may have contributed to the excessive failures on this device.

For the MOSFETs, one item was analyzed (after 150 hours HAST) that provided an unverifiable failure; five other units (also after 500 hours HAST) that were analyzed provided fused metallization of the die area. The epoxy package material was fused on the MOSFETs. This could have been the result of the high temperature they were exposed to during the HAST intervals.

A summary of the electrical and mechanical test results for both devices is given in Table 2. The devices were exposed to temperature extremes that ranged from -55 to $200^{\circ} \mathrm{C}$.

The MOSFETs experienced only four electrical failures, most of which occurred during the initial test sequences. The failures were one unverifiable, one electrostatic damage, one plastic part cracked (possible popcorn effect), and one inconclusive because the epoxy removal process damaged the die. The device that had experienced the cracked epoxy package failed post-acceleration electrical endpoints (note the stress cracks in the side view, Figure 4a). The die is shown in relation to the entire MOSFET in Figure $4 b$.

The die fracturing seen in Figure 5 may have been a result of the stress cracks shown in Figure $4 a$.

The MOSFETs did experience two lead fatigue failures. The leads broke off at the point where the lead becomes narrower. 

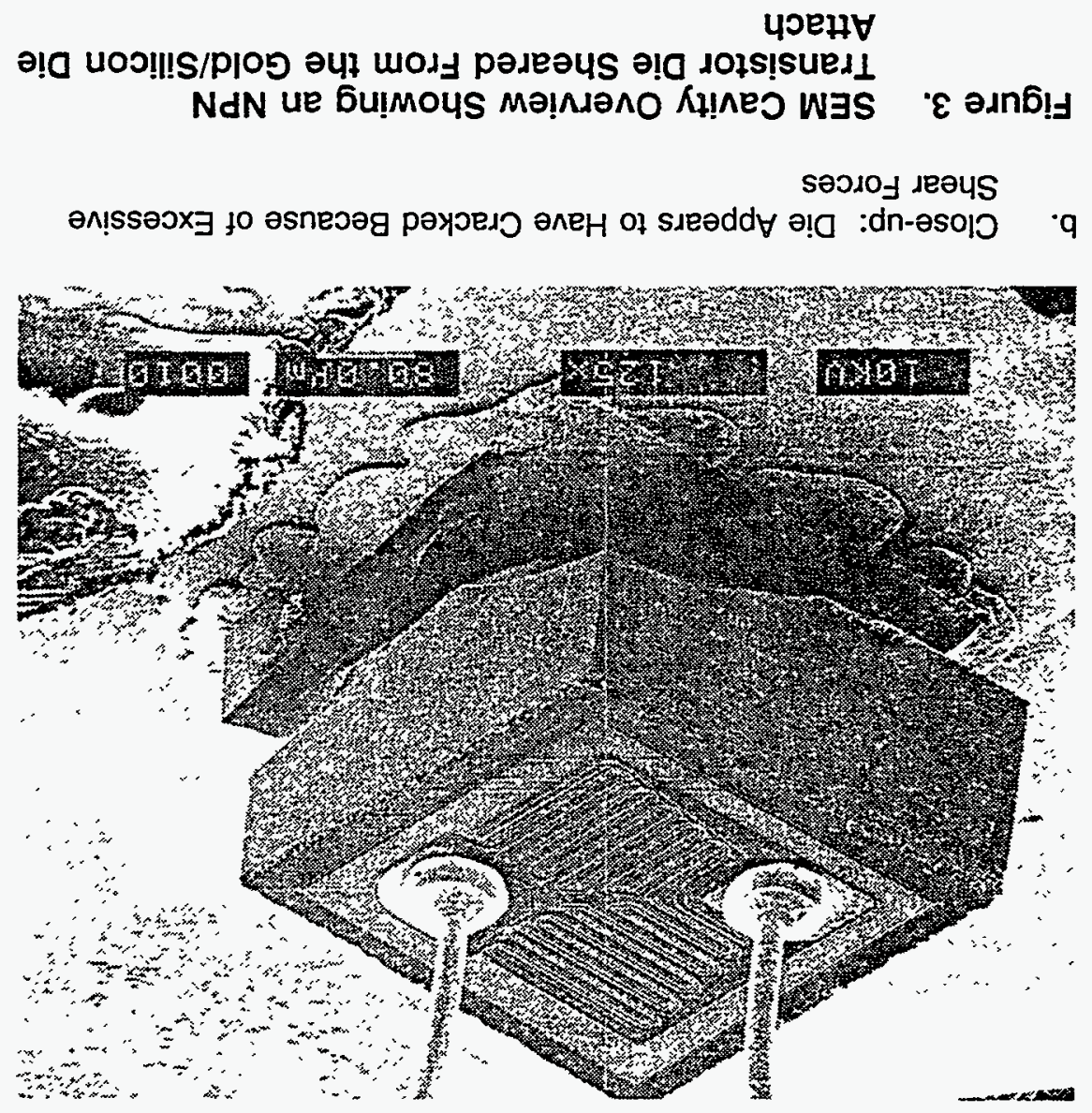

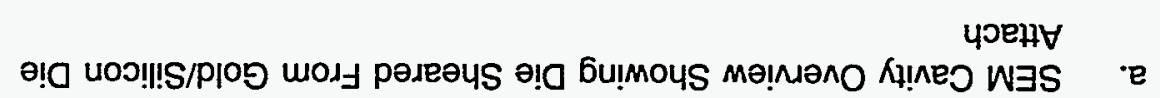

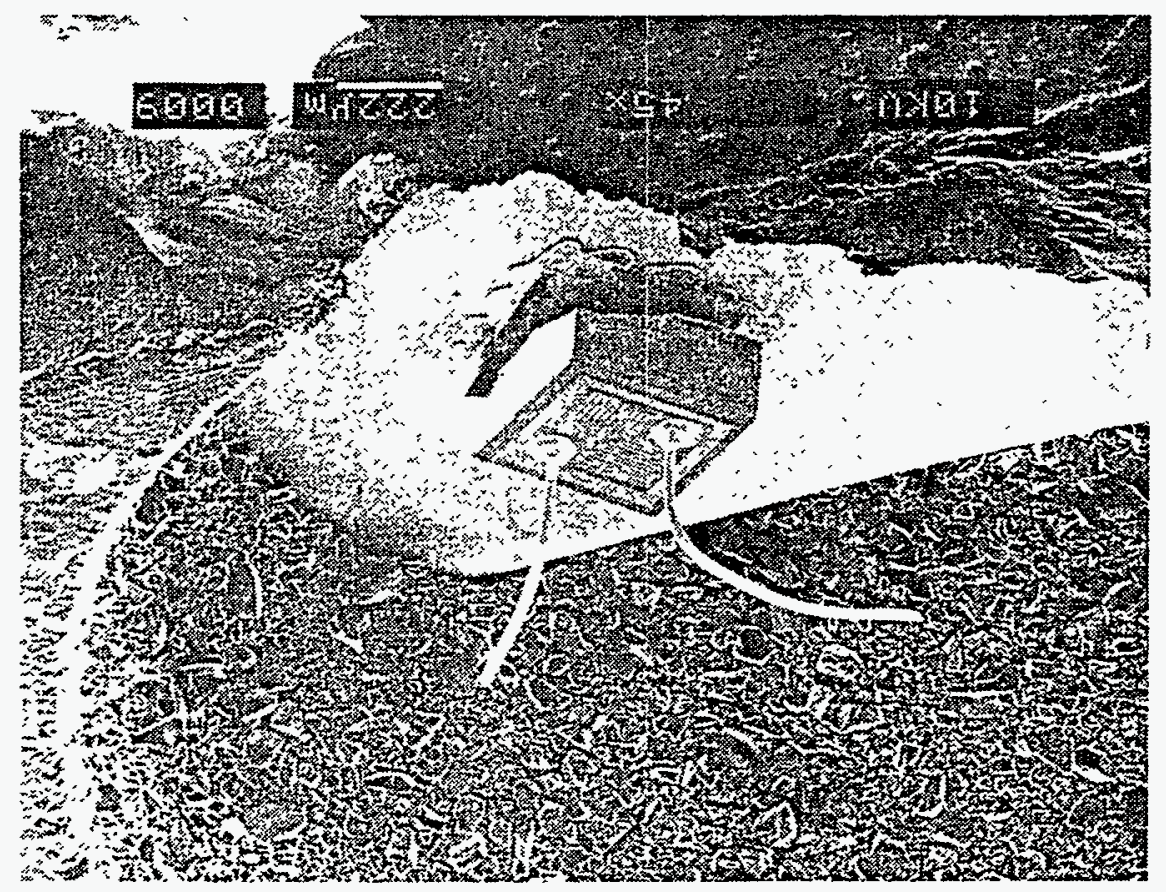


Table 2. Electrical/Mechanical Test Results (Rejects/Sample Size)

\begin{tabular}{|c|c|c|}
\hline Test & NPN Transistor & MOSFET \\
\hline $25^{\circ} \mathrm{C}$ Electrical & $4 / 301$ & $1 / 300$ \\
\hline$-55^{\circ} \mathrm{C}$ Electrical & $0 / 300$ & $1 / 299$ \\
\hline $150^{\circ} \mathrm{C}$ Electrical & $0 / 296$ & $0 / 299$ \\
\hline Constant Acceleration & 22 & 22 \\
\hline Post-Acceleration Endpoints & $2 / 22$ & $2 / 22$ \\
\hline Vibration & 20 & 20 \\
\hline Post-Vibration Endpoints & $0 / 20$ & $0 / 20$ \\
\hline Mechanical Shock & 20 & 20 \\
\hline Post-Mechanical Endpoints & $0 / 22$ & $0 / 22$ \\
\hline High-Temperature Storage & 10 & 129 \\
\hline Post-Temperature Endpoints & $2 / 10$ & $0 / 129$ \\
\hline Lead Fatigue & $0 / 10$ & $2 / 10$ \\
\hline Post-Lead Fatigue Electrical & $0 / 9$ & $0 / 8$ \\
\hline Lead Tension & $0 / 10$ & $0 / 10$ \\
\hline Collector Lead & $0 / 10$ & \\
\hline Temperature Cycling & 20 & 129 \\
\hline Post-Temperature Endpoints & $0 / 20$ & $0 / 129$ \\
\hline Fine Leak & $0 / 20$ & $50 / 50$ \\
\hline Gross Leak & $20 / 20$ & $50 / 50$ \\
\hline Pre-Burn-in Electrical & $1 / 153$ & \\
\hline Pre-Op. Life Electrical & 20 & \\
\hline Burn-in & 153 & \\
\hline Post-Burn-in Electrical & $0 / 153$ & \\
\hline Op. Life & 20 & \\
\hline Post-Op. Life Electrical & $0 / 20$ & \\
\hline HTRB & 211 & 45 \\
\hline Post-HTRB Electrical & $1 / 211$ & $0 / 45$ \\
\hline Post-HTRB Solderability & $0 / 22$ & $0 / 22$ \\
\hline Pre-HTFB Electrical & & $0 / 45$ \\
\hline HTFB & & 45 \\
\hline Post-HTFB Endpoints & & $0 / 45$ \\
\hline Post-HTRB Endpoints & & $0 / 45$ \\
\hline Pre-Bias Electrical & & $0 / 45$ \\
\hline Bias Life & & 45 \\
\hline Post-Bias Life Endpoints & & $0 / 45$ \\
\hline
\end{tabular}




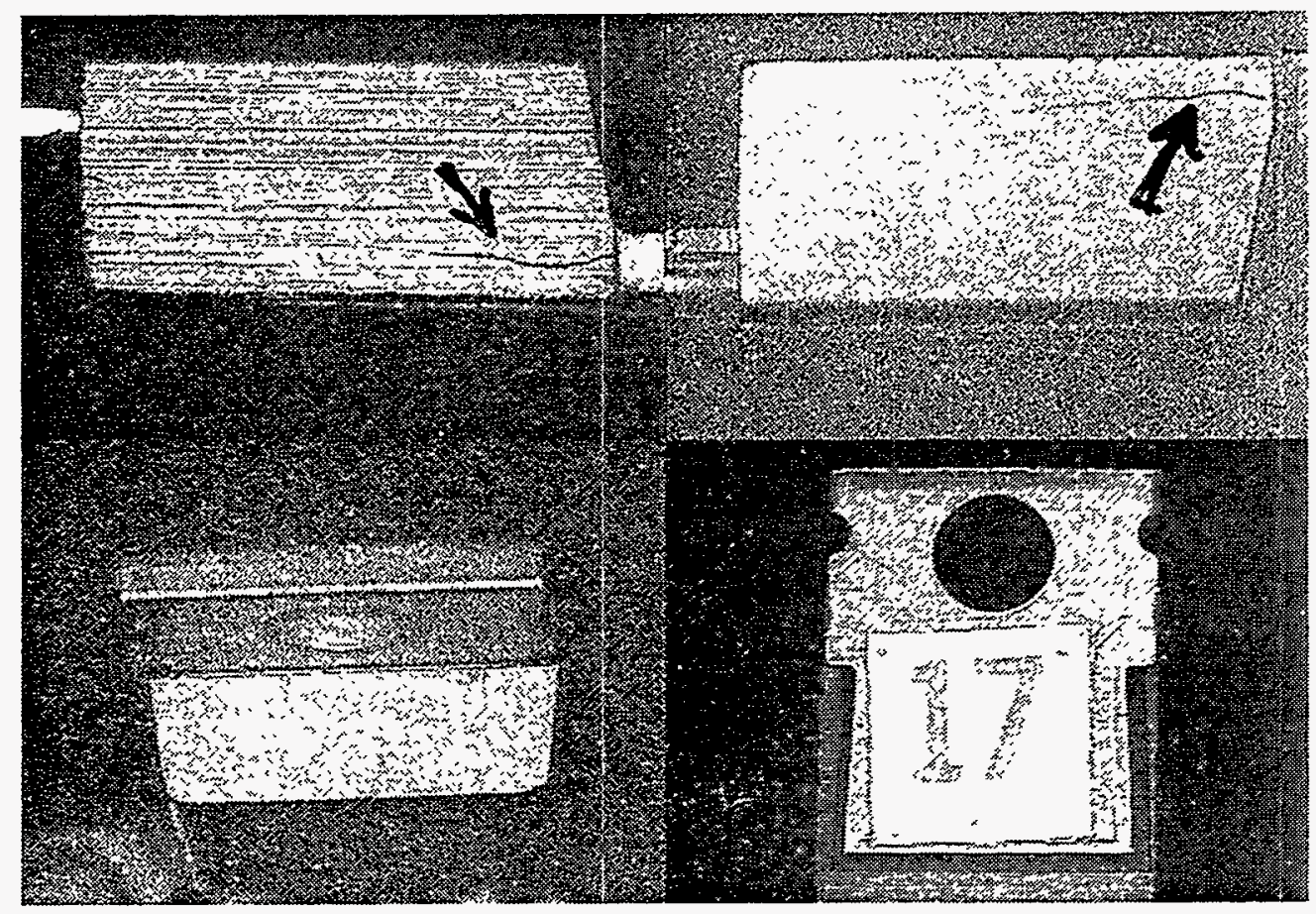

a. Package Stress Cracks

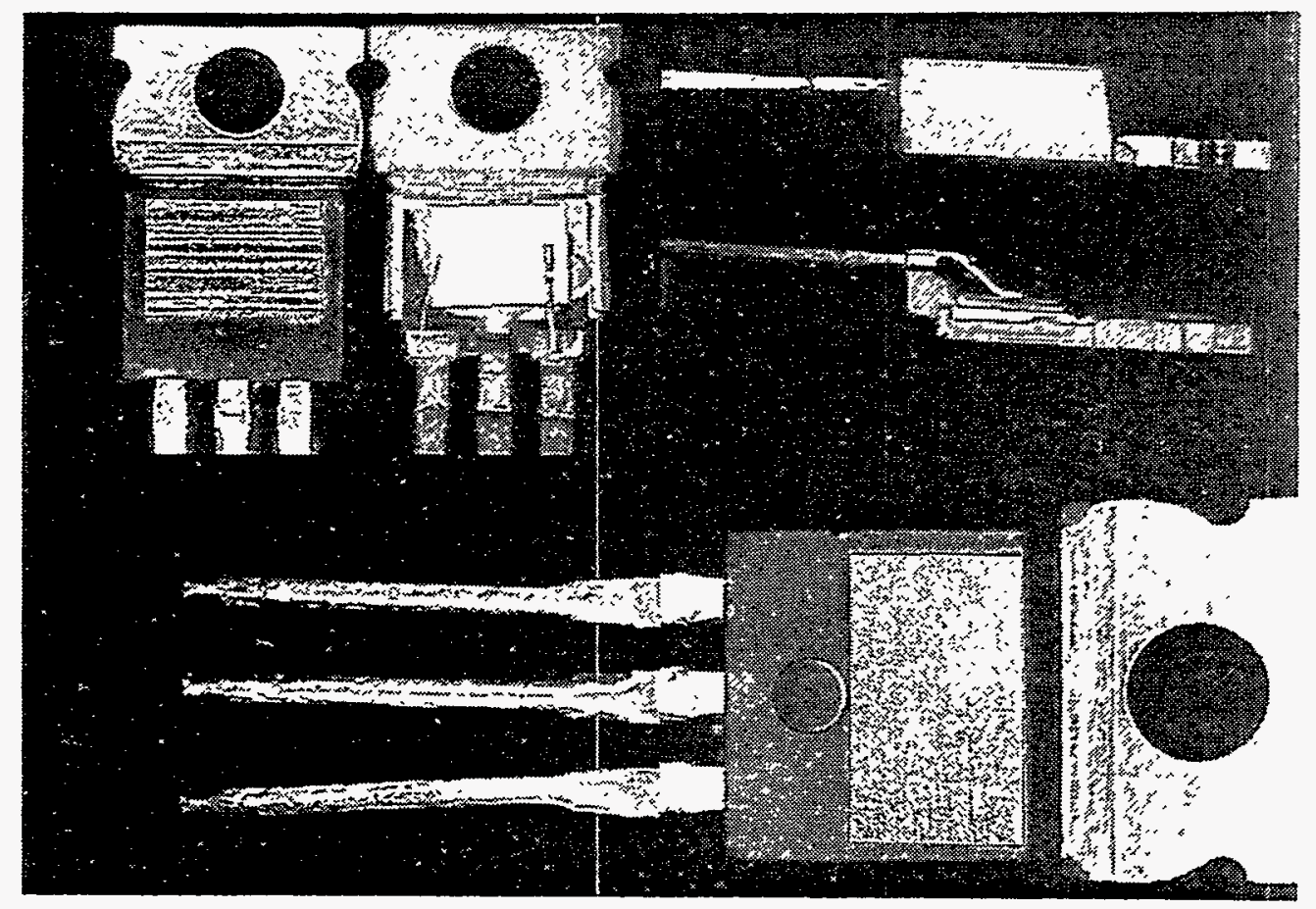

b. Die in Relation to Entire MOSFET

Figure 4. MOSFET With Cracked Epoxy Package 


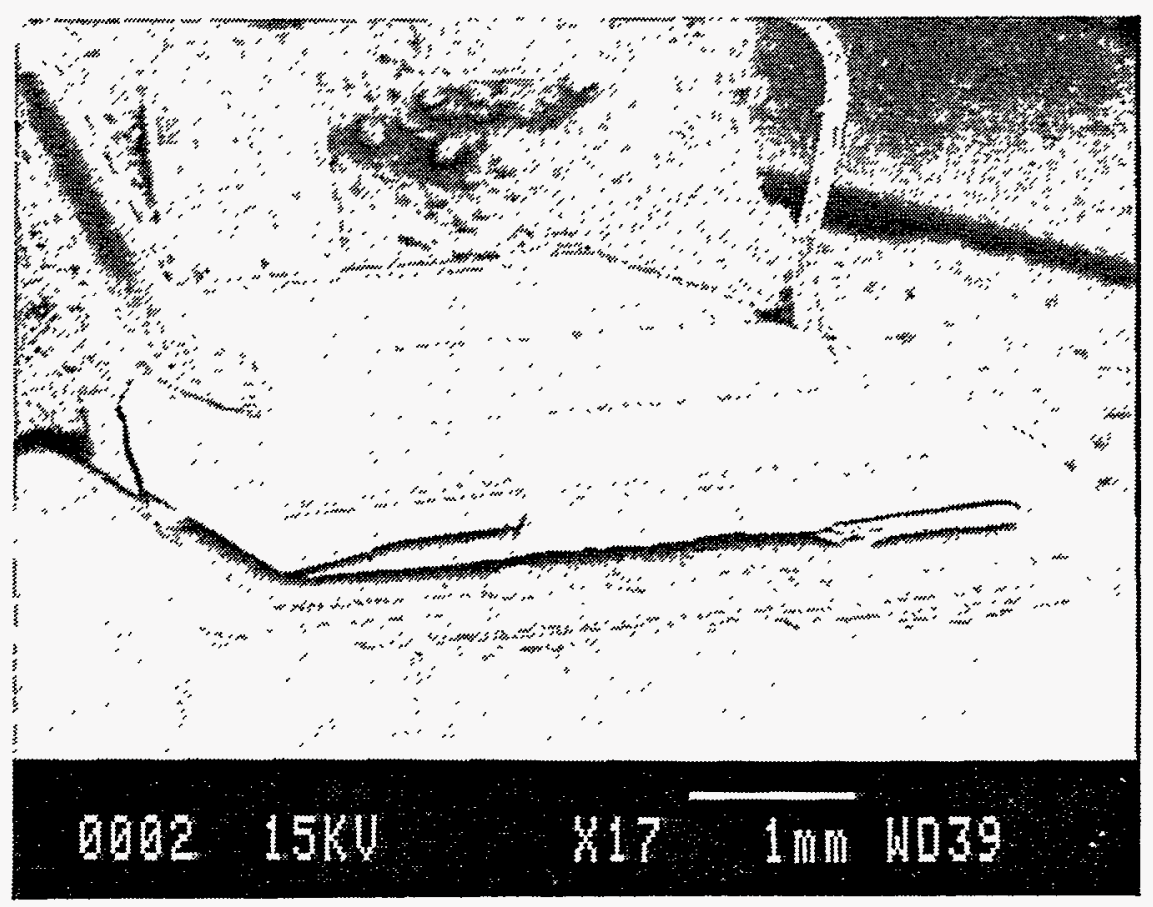

a. Entire Die

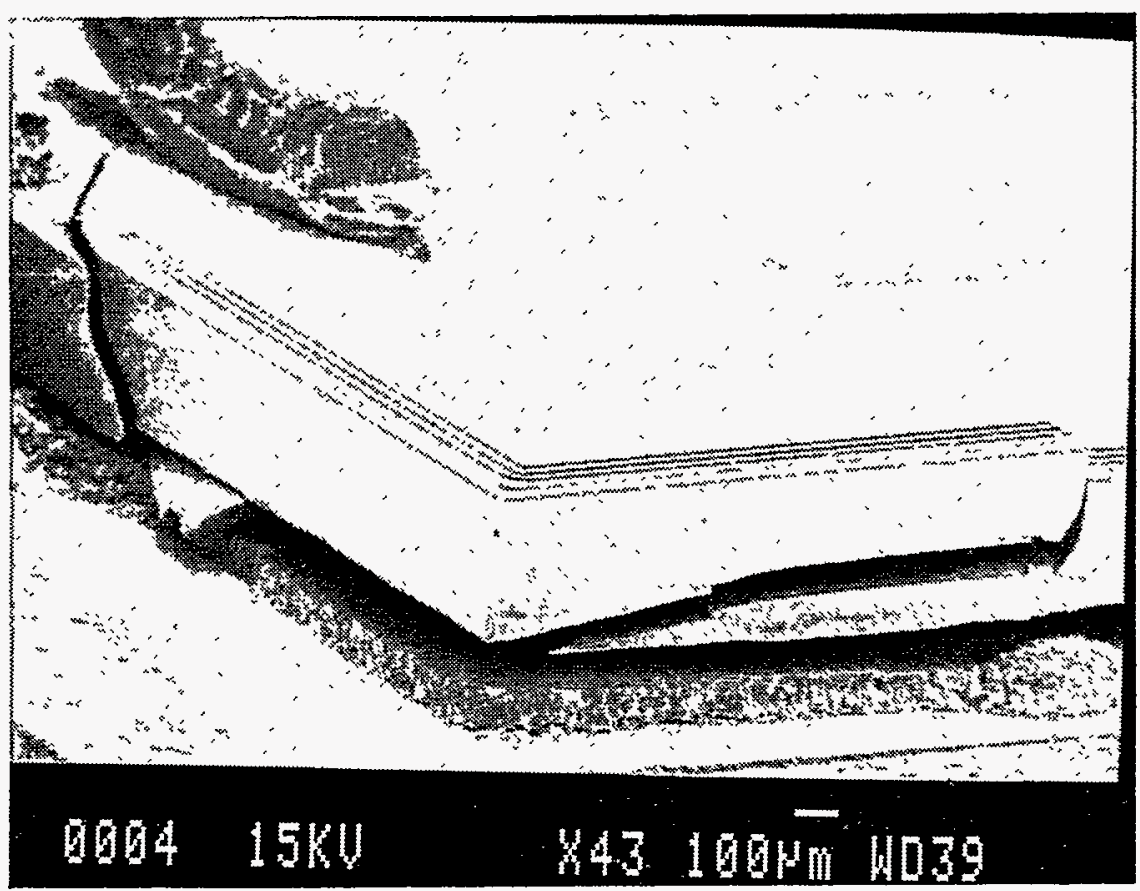

b. Left View of Die

Figure 5. SEM Photo of Fractured MOSFET Die 


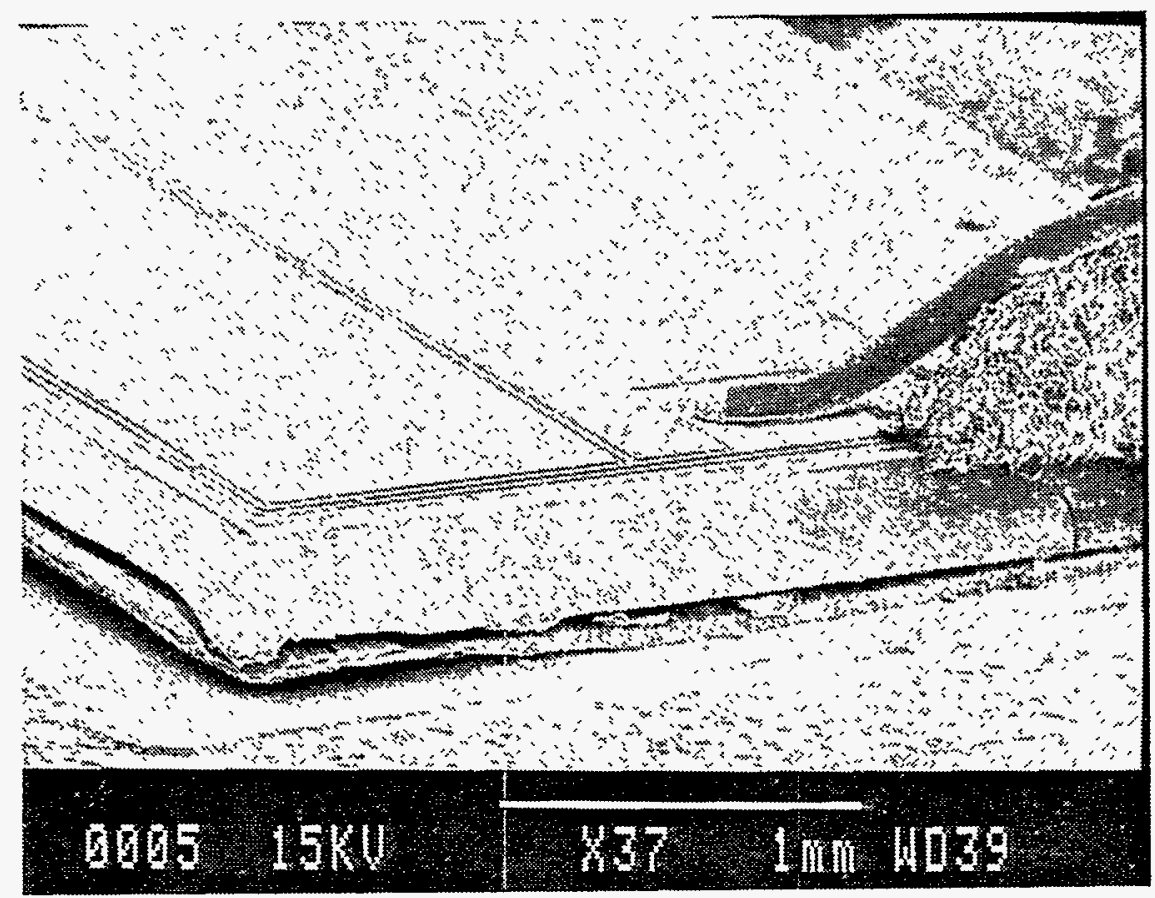

c. Right View of Die

Figure 5 Continued. SEM Photo of Fractured MOSFET Die

Lead integrity test results for both part types can be seen in Table 3.

The NPN transistors experienced only nine electrical failures, most of which again occurred during the initial test sequences. The failures were in four categories: unverifiable, electrostatic damage, electrical overstress, and poor die attach. The failure with poor die attach occurred after temperature storage electricals. The NPN transistor group also experienced a lead fatigue failure; the lead became detached during the post-lead fatigue electrical test.

The NPN transistors were exposed to additional high-temperature cycling, 45 cycles total (Table 4). The additional temperature cycling was to verify the temperature sensitivity of the devices. The failures have not been evaluated.

\section{Moisture Absorption and Failure Analysis Concerns}

Plastic encapsulated devices present two particular problems: (1) their ability to absorb moisture must be dealt with and (2) a capability to perform adequate failure analysis must be achieved.

Removal of the plastic material for inspection by chemical or mechanical techniques subjects the die, wires, and lead frame to mechanical and/or chemical forces which may cause substantial damage. Removing the lid of a metal package for inspection subjects the device to substantially lower mechanical/chemical forces. If a plastic device needs to be evaluated for corrosion to the die, mechanical techniques should be used. If visuals on the die and wires need to be made, the chemical methods should not be used. The most common technique is to drill a hole in the top of the package. For epoxy, the hole is filled with red fuming nitric acid while heat is applied.' Exposure 
Table 3. Lead Integrity Test Results $(n=10)$

\begin{tabular}{||c|c|c||}
\hline \hline Test & MOSFET & NPN Transistor \\
\hline Lead Fatigue & 2 Rejects & No Rejects \\
\hline Lead Tension (lb) & & \\
Average: & 29.93 & 12.48 \\
Maximum: & 36.0 & 13.60 \\
Minimum: & 20.4 & 9.30 \\
\hline Collector Pull (lb) & & \\
Average: & & 12.92 \\
Maximum: & & 13.7 \\
Minimum: & & 11.3 \\
\hline \hline
\end{tabular}

* Lead failed during post-lead fatigue electrical.

Table 4. NPN Transistor Temperature Cycling

\begin{tabular}{||c|c|c|c|c|c|c|c|c|c||}
\hline & \multicolumn{10}{|c||}{ Cycle } \\
\cline { 2 - 11 } & 5 & 10 & 15 & 20 & 25 & 30 & 35 & 40 & 45 \\
\hline Rejects & 0 & 2 & 0 & 2 & 1 & 0 & 1 & 0 & 0 \\
\hline $\begin{array}{c}\text { Number } \\
\text { Tested }\end{array}$ & 25 & 24 & 21 & 21 & 19 & 18 & 17 & 16 & 15 \\
\hline \hline
\end{tabular}

time is critical because overexposure will attack the metallization. Chemical techniques are not recommended when corrosion is suspected.

Because absorption and permeation of water through polymer materials are inevitable, the most serious problem in plastic encapsulated devices is aluminum metallization corrosion in moist atmospheres, which leads to functional failures of the devices. ${ }^{2}$ There are two paths for moisture penetration. One is through the material itself and the other one is through the interface of the encapsulation material and the lead frame, gold wire, and chip.
Reduced corrosion failure rates have been achieved by perfecting the glassivation (low phosphorous, no pinholes) and reducing metallization defects (for example, hillocks and scratches) which may form localized electrolytic cells and start corrosion. ${ }^{1}$

The effort to make the die hermetic is being made by using silicon nitride as glassivation. The combination of this and new plastics provides possibilities of extending the lifetime of plastic devices. Improved passivation techniques have removed interconnect corrosion as a reliability problem, but bond pad corrosion remains an issue. Bond pad corrosion typically occurs in the presence of ionic contamination at the passivation opening of the microcircuit. Chlorine presence in the 
bond pad has been determined to be the cause of the corrosion. The molding compounds of plastics have a varying amount of chlorine.

The nonhermetic issue and the inability to perform a satisfactory analysis will remain as concerns in the use of plastic semiconductors for high-reliability military applications. Industry and government (Navy Crane) have combined resources to further study the use and improvement of plastic semiconductors.

\section{Accomplishments}

During testing of two types of plastic semiconductor devices, the NPN transistors experienced the highest fallout (catastrophic). Approximately $61 \%$ failed after 30 hours in the initial phases of the HAST intervals. The MOSFETs appeared to be more robust throughout the complete HAST intervals. They experienced no failures (catastrophic) after 70 hours of HAST intervals. The reason for the robustness of the MOSFETs was not definitely determined but could be partly due to the fact that the MOSFET is a bigger package, and therefore, the fabrication process may differ from that of the NPN transistor.

Silicon nitride is being used as glassivation in the effort to make the die hermetic. The combination of this and new plastics provides possibilities for extending the lifetime of plastic devices. Improved passivation techniques have removed interconnect corrosion as a reliability problem, but bond pad corrosion remains a concern.

The nonhermetic nature of plastic semiconductor devices and the inability to perform a satisfactory analysis on them will both be topics for further study by industry and government in the search for high- reliability military applications of these devices. 


\section{References}

'Nicholas Lycoudes, "The Reliability of Plastic Microcircuits in Moist Environments." Motorola Reliability Quality Handbook, 1992.

${ }^{2}$ Noriyuki Kinjo, Masatsugu Ogata, Kunihiko Nishi, and Aizou Kaneda, "Epoxy Molding Compounds as Encapsulation Materials for Microelectronic Devices." Advances in Polymer Science, 1988. 


\section{Appendix}

\section{NPN Transistor Test Data}


Statistical Sumary

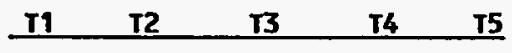

\section{Icbo(nh)}

$\begin{array}{llllll}\text { Max } & 1.2 & 1.10 & .20 & .89 & .14 \\ \text { Min } & .01 & .020 & .130 & .050 & .10 \\ \text { Avg } & .22 & .17 & .16 & .14 & .12\end{array}$

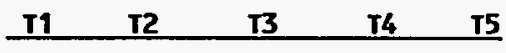

\section{Iebo(m)}

$\begin{array}{lllll}8.0 & 4.6 & .14 & 6.9 & .13\end{array}$

$\begin{array}{lllll}.03 & .060 & .070 & .040 & .05\end{array}$

$\begin{array}{lllll}.03 & .23 & .094 & .23 & .079\end{array}$

$\begin{array}{lllll}-8.52 & -9.67 & 14.36 & -11.25 & 11.51\end{array}$

\section{Hfe3}

$\begin{array}{lllll}216.0 & 209 & 202.0 & 209.0 & 197.6\end{array}$

$\begin{array}{lllll}148.5 & 159.2 & 158.2 & 155.9 & 156.3\end{array}$

$\begin{array}{llllll}179.64 & 176.1 & 171.4 & 174.4 & 168.7\end{array}$

$\begin{array}{lllll}21.93 & 22.35 & 21.54 & 21.89 & 21.61\end{array}$

\section{Vbeon(miv)}

$\begin{array}{lllll}607.5 & 609.5 & 607.5 & 608.5 & 609.5\end{array}$

$\begin{array}{lllll}590.0 & 599.5 & 599.0 & 596.0 & 603.0\end{array}$

$\begin{array}{lllll}598.46 & 604.8 & 604.8 & 604.5 & 607.2\end{array}$

$\begin{array}{lllll}45.01 & 48.98 & 47.20 & 46.72 & 49.14\end{array}$

Vces(an)

$\begin{array}{lllll}539.0 & 305.0 & 256.0 & 307.5 & 258.5\end{array}$

$\begin{array}{llllll}233.0 & 234.5 & 237.0 & 235.0 & 238.0\end{array}$

$\begin{array}{lllll}246.8 & 245.2 & 244.1 & 247.2 & 245.4\end{array}$

$\begin{array}{lllll}20.98 & 28.28 & 31.35 & 28.13 & 31.15\end{array}$

\section{BVceo}

$\begin{array}{lllll}53.05 & 52.75 & 52.45 & 52.90 & 52.55\end{array}$

$\begin{array}{lllll}47.4 & 50.05 & 50.6 & 50.0 & 50.65\end{array}$

$\begin{array}{llllll}50.8 & 51.58 & 51.94 & 51.62 & 52.0\end{array}$

$\begin{array}{lllll}32.39 & 36.74 & 39.65 & 35.98 & 39.45\end{array}$

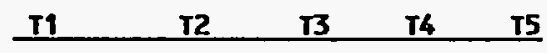

Hfe1

$\begin{array}{lllll}199.8 & 191.9 & 183.8 & 189.2 & 178.9\end{array}$

$\begin{array}{llllll}106.5 & 137.4 & 141.5 & 132.7 & 139.4\end{array}$

$\begin{array}{lllll}163.95 & 159.7 & 155.4 & 156.5 & 151.86\end{array}$

$\begin{array}{lllll}21.18 & 22.09 & 21.15 & 21.67 & 21.14\end{array}$

Hfe4

$\begin{array}{lllll}212.0 & 207.0 & 199.2 & 207.0 & 196.6\end{array}$

$\begin{array}{lllll}159.9 & 110.6 & 159.4 & 158.7 & 157.9\end{array}$

$\begin{array}{llllll}178.32 & 175.6 & 170.9 & 175.1 & 169.2\end{array}$

$\begin{array}{lllll}22.75 & 23.07 & 22.28 & 22.59 & 22.27\end{array}$

Vbeon(miV)

$\begin{array}{lllll}715.0 & 716.0 & 715.0 & 716 & 716.5\end{array}$

$\begin{array}{lllll}699.0 & 707.0 & 707.0 & 705 & 710.0\end{array}$

$\begin{array}{lllll}707.2 & 712.3 & 712.0 & 712.1 & 714.5\end{array}$

$\begin{array}{lllll}47.59 & 50.61 & 49.17 & 48.99 & 49.88\end{array}$

Vbes ( $\mathrm{m} N)$

$\begin{array}{lllll}843.0 & 844.0 & 843.0 & 845.5 & 844.5\end{array}$

$\begin{array}{lllll}834.5 & 840.0 & 841.0 & 839.0 & 842.5\end{array}$

$\begin{array}{lllll}838.7 & 842.3 & 841.8 & 842.3 & 843.5\end{array}$

$\begin{array}{llllll}53.76 & 60.21 & 62.83 & 53.23 & 61.38\end{array}$

BVcbo

$\begin{array}{lllll}137.6 & 137.2 & 137.0 & 137.2 & 136\end{array}$

$\begin{array}{lllll}117.0 & 131.2 & 133.1 & 131.0 & 133\end{array}$

$\begin{array}{lllll}133.87 & 134.5 & 134.5 & 134.4 & 134.3\end{array}$

$\begin{array}{lllll}36.26 & 39.97 & 41.29 & 39.71 & 44.46\end{array}$

$S / N=10^{\star} \log$ (base 10$)\left[\right.$ Avg^2/Sigma^2] $^{\wedge}$

T1 - 100\% Amb. Elec

T2 - Pre Power B/I Elec

T3 - Post Power B/I

T4 - Post Op Life

TS - POst HTRB 


\section{NPN Transistor Inspection Flow}

Rej/Sample

Size

$4 / 301$

$0 / 300$

$2 / 300$

22

$1 / 22$

22

$2 / 22$

22

$0 / 22$

10

$2 / 10$

$0 / 10$

$0 / 9$

\section{Test Description}

25 C Electrical

s/n 131 (Iebo-15.13nA), s/n 257 (Icbo-655nA), s/n 184 (Icbo-248nA), s/n 297 (Icbo-1.3 uA)

$-55 \mathrm{C}$ Electrical

$150 \mathrm{C}$ Electrical s/n 257 (Icbo-10.34uA), s/n 297 (Icbo-20.5uA)

Constant Acceleration

$25 \mathrm{~kg}$ 's in 6 directions

Mil-Std-750, Method 2006

Post Acceleration Endpoints

s/n 17 (Icbo-ovr),

$\mathrm{s} / \mathrm{n} 21$ (888nA)

Vibration

Mil-Std-750, Method 2056

$20 \mathrm{G}$, freq. range $100-2 \mathrm{k} \mathrm{Hz}$

4 minutes minimum ( 4 times in $\mathrm{X} 1, \mathrm{Y} 1, \mathrm{Z} 1$ direction)

Post Vibration Endpoints

s/n 17 (Icbo-ovr),

s/n 21 (Icbo-492na)

Mechanical Shock

Mil-Std-750, Method 2016

Duration $.5 \mathrm{~ms}$ for 5 pulses in each direction

$1500 \mathrm{~g}$ 's

Post Mechanical Endpoints

High Temperature Storage

200 C, 48 Hrs. min.

Post Temp. Endpoints

s/n 25 (Vces-575mV),

s/n 27 (Vces-562mv)

Lead Fatigue

Mil-Std-750, Method 2036, Cond. E

Post Lead Fatigue Electrical, 9 tested, one lead detached 


\begin{tabular}{|c|c|}
\hline $0 / 10$ & $\begin{array}{l}\text { Lead Tension } \\
\text { Pull Base and Emmitter leads to destruction } \\
6 \mathrm{lbs} \text {. min. }\end{array}$ \\
\hline $0 / 10$ & $\begin{array}{l}\text { Collector Lead } \\
\text { Pull Collector to destruction } \\
6 \mathrm{lbs} \text {. min. }\end{array}$ \\
\hline 20 & $\begin{array}{l}\text { Temperature Cycling } \\
5 \text { Cycles, }(-55 \mathrm{C})-(+125 \mathrm{C}), 30 \text { minutes min soak } \\
\text { Mil-Std-750, 1051; Mil-Std-202, 107, Cond. B }\end{array}$ \\
\hline $0 / 20$ & Post Temp. Endpoints \\
\hline $0 / 20$ & $\begin{array}{l}\text { Fine Leak } \\
\text { Mil-Std-750, Method 1071, Cond. H1, } 5 \times 10 \mathrm{e}-8 \mathrm{cc} / \mathrm{sec}\end{array}$ \\
\hline $20 / 20$ & $\begin{array}{l}\text { Gross Leak } \\
\text { Mil-Std-750, Method 1071, Cond. C }\end{array}$ \\
\hline $1 / 153$ & $\begin{array}{l}\text { Pre Burn-In Electrical } \\
\text { s/n } 184 \text { (Icbo-119nA) }\end{array}$ \\
\hline 20 & Pre-OP Life Electrical \\
\hline 153 & $\begin{array}{l}\text { Burn-In } \\
48 \mathrm{Hrs}, \mathrm{Vce}=24, \mathrm{Pt}=400 \mathrm{~mW} \\
\text { Mil-Std-750, Method } 1039 \text {, Cond B. }\end{array}$ \\
\hline $0 / 153$ & Post B/I Electrical \\
\hline 20 & $\begin{array}{l}\text { Op Life Test } \\
\mathrm{Vcb}=10, \mathrm{Pt}=400 \mathrm{~mW}\end{array}$ \\
\hline $0 / 20$ & Post Op Life Electrical \\
\hline 211 & $\begin{array}{l}\text { HTRB } \\
168 \text { Hrs., } 150 \mathrm{C} \min , \mathrm{Vcb}=32\end{array}$ \\
\hline $1 / 211$ & $\begin{array}{l}\text { Post HTRB Electrical } \\
\text { s/n } 118 \text { (Vces-327mV) }\end{array}$ \\
\hline $0 / 22$ & Post HTRB Solderability \\
\hline
\end{tabular}




\title{
MOSFET Inspection Flow
}

\author{
Sample \\ $\underline{\text { Size }}$ \\ Test Description \\ 1/300 25 C Electrical \\ $\mathrm{s} / \mathrm{n} 18$ (Vth-9.92mV, BVDss-11.46mV, Gfs-26.08M Idss-99.13mA) \\ 2/300 $\quad-55$ C Electrical \\ s/n 18 (Vth-8.32, Vds-2.89V); \\ $\mathrm{s} / \mathrm{n} 300$ (Vth-7.64, Vds-4V) \\ $1 / 300 \quad 150 \mathrm{C}$ Electrical \\ $\mathrm{s} / \mathrm{n} 18$ (Vth-23.42mV, Idss-12.2mA, BVdss-19.97mV) \\ 22 Constant Acceleration \\ $25 \mathrm{~kg}$ 's in 6 directions \\ Mil-Std-750, Method 2006 \\ $2 / 22$ \\ Post Acceleration Endpoints \\ s/n 17 (Idss-27.1A, Rds-73.35); \\ $\mathrm{s} / \mathrm{n} 20$ (Vth-20.58mV, Idss-10.41mA, BVdss-22.54mV) \\ 20 \\ Vibration \\ Mil-Std-750, Method 2056 \\ $20 \mathrm{G}$, freq. range $100-2 \mathrm{k} \mathrm{Hz}$ \\ 4 minutes minimum (4 times in $\mathrm{X} 1, \mathrm{Y} 1, \mathrm{Z} 1$ direction) \\ 0/20 Post Vibration Endpoints \\ 20 \\ Mechanical Shock \\ Mil-Std-750, Method 2016 \\ Duration $.5 \mathrm{~ms}$ for 5 pulses in each direction \\ 1500 g's \\ $0 / 20$ \\ Post Mechanical Endpoints \\ 129 \\ High Temperature Storage \\ $200 \mathrm{C}, 48$ Hrs. min. \\ 0/129 Post Temp. Endpoints \\ 2/10 Lead Fatigue \\ Mil-Std-750, Method 2036, Cond. E \\ 0/8 Post Lead Fatigue Electrical \\ 0/10 Lead Tension \\ Pull Base and Emmitter leads to destruction \\ $6 \mathrm{lbs}$. min. \\ 129 Temperature Cycling \\ 5 Cycles, $(-55 \mathrm{C})-(+125 \mathrm{C}), 30$ minutes min soak \\ Mil-Std-750, 1051; Mil-Std-202, 107, Cond. B
}


$0 / 129$

$50 / 50$

$50 / 50$

$0 / 45$

45

$0 / 45$

45

$0 / 45$

$0 / 22$

$0 / 45$

45

$0 / 45$
Post Temp. Endpoints

Fine Leak

Mil-Std-750, Method 1071, Cond. H1, 5 x 10e-8 cc/sec

Gross Leak

Mil-Std-750, Method 1071, Cond. C

Pre HTFB Electrical

HTFB

$\mathrm{t}=24$ hrs., Temp $=150 \mathrm{C}, \mathrm{Vgs}=16 \mathrm{~V}, \mathrm{VDS}=0 \mathrm{~V}, \mathrm{R}=10 \mathrm{k}$

Post HTFB Endpoints

HTRB

$\mathrm{t}=168$ hrs., Temp $=150 \mathrm{C}, \mathrm{Vds}=40 \mathrm{~V}, \mathrm{Vgs}=0 \mathrm{~V}$

Post HTRB Endpoints

Post HTRB Solderability

Pre Bias Electrical

Bias Life

$\mathrm{t}=40 \mathrm{hrs}$., Temp $=150 \mathrm{C}, \mathrm{Vgs}=16 \mathrm{~V}, \mathrm{Vds}=0 \mathrm{~V}, \mathrm{R}=10 \mathrm{k}$

Post Bias Life Endpoints 